\title{
Heart rate variability and blood pressure among Japanese men and women: a community-based cross-sectional study
}

\begin{abstract}
Hiromi Mori ${ }^{1}$, Isao Saito ${ }^{2}$, Eri Eguchi ${ }^{1}$, Koutatsu Maruyama ${ }^{3}$, Tadahiro Kato ${ }^{4}$ and Takeshi Tanigawa ${ }^{1}$
Heart rate variability (HRV) is associated with blood pressure levels; however, very few studies have correlated HRV to lifestyle in the general population. We investigated 1418 men and 2040 women aged 40-74 years and measured the HRV indices in the time and frequency domains using a 5-min R-R interval recording. Multiple linear regression analyses were used to estimate the association between HRV and blood pressure levels after adjustment for major confounders. HRV indices were not associated with systolic blood pressure levels in men, whereas in women, one-s.d. (1-s.d.) increment of s.d. of normal R-R intervals (SDNN) was associated with a 1.21-mm Hg decrease in systolic blood pressure after adjusting for several confounders $(P<0.05)$. In addition, a 1-s.d. increment of SDNN corresponded with 1.00 and $1.10 \mathrm{~mm} \mathrm{Hg}$ reductions in diastolic blood pressure in men and women, respectively $(P<0.05)$. When stratified by the use or nonuse of antihypertensive medication, these inverse associations were more evident in the nonuser group. Furthermore, among men not using antihypertensive medication, reduced HRV was associated with increased systolic blood pressure levels in nondrinkers. The data suggest that HRV reflects diastolic blood pressure better than systolic blood pressure levels for both sexes and that alcohol intake strongly affects systolic blood pressure levels in men, which may have weakened the association with HRV.
\end{abstract}

Hypertension Research (2014) 37, 779-784; doi:10.1038/hr.2014.73; published online 20 March 2014

Keywords: autonomic nervous system; blood pressure; epidemiology; heart rate variability

\section{INTRODUCTION}

Hypertension is well established as one of the major risk factors for cardiovascular disease in Japan. ${ }^{1}$ Despite several population-based studies reporting that both stroke incidence and mortality decline following greatly reductions in blood pressure, ${ }^{1-3}$ hypertension remains responsible for $43.0 \%$ of the population-attributable risk of stroke and $17.9 \%$ of acute myocardial infarction, ${ }^{4}$ as suggested by a Japanese cohort study. ${ }^{5}$

Autonomic nervous function has a significant role in the circulatory system and in blood pressure regulation. Spectral analysis of heart rate variability (HRV) is a noninvasive tool that is widely used to assess autonomic nervous function. ${ }^{6}$ Impaired autonomic nervous function has been implicated in the development of coronary heart disease, $^{7,8}$ all-cause mortality ${ }^{9-11}$ and hypertension. ${ }^{12-14}$ The Atherosclerosis Risk in Communities study has reported that HRV is significantly lower in hypertensive participants, with participants in the lowest HRV quartile having a 2.44 times greater risk of hypertension than those in the highest quartile during the 3-year follow-up period. $^{12}$ Furthermore, a recent report from the Atherosclerosis Risk in Communities study found that the hazard ratio for hypertension development during the 9-year follow-up period was 1.36 times higher for participants in the lowest HRV quartile of square root of the mean-squared differences (rMSSD) compared with those in the highest quartile. ${ }^{13}$ In a 4-year Framingham Heart cohort study, ${ }^{14}$ low-frequency (LF) power was found to be associated with hypertension incidence during the 4-years follow-up period, with an odds ratio of 1.38 per 1-s.d. of LF decrement. Therefore, impaired autonomic nervous function and decreased HRV may be underlying causes of hypertension, and estimation of HRV may improve hypertension risk prediction.

In addition, lifestyle is associated with HRV and blood pressure. ${ }^{15}$ The Whitehall II study showed that adverse health-related lifestyle, including smoking, little or no vigorous exercise, poor diet, high alcohol consumption and lack of physical activity, was associated with adverse HRV. ${ }^{16}$ Alcohol consumption and obesity are key factors associated with elevated blood pressure levels and are linked with increased cardiovascular disease risk. However, there are very few studies on HRV condition related to such lifestyles in the Japanese population. Therefore, our aim was to examine the association of

${ }^{1}$ Department of Public Health, Ehime University Graduate School of Medicine, Ehime, Japan; ${ }^{2}$ Department of Basic Nursing and Health Science, Ehime University Graduate School of Medicine, Ehime, Japan; ${ }^{3}$ Department of Basic Medical Research and Education Ehime University Graduate School of Medicine, Ehime, Japan and ${ }^{4}$ Department of Applied Bioresource Science, Ehime University The United Graduate School of Agricultural Sciences, Ehime, Japan 
HRV with blood pressure levels by measuring the 5-min R-R intervals in a population-based sample of Japanese.

\section{METHODS}

\section{Study population}

We recruited the subjects from participants in an annual health checkup from 2009 to 2011 at Ozu City, Ehime Prefecture, Japan. A total of 3600 participants ( 1485 men and 2115 women) aged between 40 and 74 years were recruited. We excluded participants with premature beat (39 men and 38 women), atrial fibrillation (12 men and 8 women) and with missing HRV data (16 men and 29 women). Therefore, a total of 3458 (1418 men and 2040 women) participants were included in the analyses. No substantial differences were found in the characteristics between included and excluded participants. The ethics committee of the Ehime University School of Medicine approved the study. The participants received instructions about the study procedure, and all the participants provided written informed consent

\section{Measurements}

Blood pressure was measured after a 5 -mi rest in a seated position. An automatic sphygmomanometer (BP-103i II, Omron Colin, Kyoto, Japan) was used to measure blood pressure on the right arm twice, and the mean values of the two measurements were used for the analyses. Hypertension was defined as a systolic blood pressure of $\geqslant 140 \mathrm{~mm} \mathrm{Hg}$ and/or diastolic blood pressure of $\geqslant 90 \mathrm{~mm} \mathrm{Hg}$ and/or current use of antihypertensive medication. ${ }^{17}$

Body mass index (BMI) was calculated as the participant's weight $(\mathrm{kg})$ divided by the square of standing height $\left(\mathrm{m}^{2}\right)$. We defined diabetes by hemoglobin Alc (Japan Diabetes Society (JDS)) level of $\geqslant 6.1 \%$ or pharmacological treatment for diabetes. ${ }^{18}$ Dyslipidemia was classified by a high-density lipoprotein cholesterol level of $\leqslant 1.03 \mathrm{mmoll}^{-1}\left(40 \mathrm{mg} \mathrm{dl}^{-1}\right)$, a low-density lipoprotein cholesterol level of $\geqslant 3.62 \mathrm{mmoll}^{-1}\left(140 \mathrm{mg} \mathrm{dl}^{-1}\right)$, a triglyceride level of $\geqslant 1.69 \mathrm{mmoll}^{-1}\left(150 \mathrm{mg} \mathrm{dl}^{-1}\right)$ or pharmacological treatment for dyslipidemia. ${ }^{19}$ Trained interviewers administered the questionnaires and assessed smoking status, alcohol consumption status and physical activity. Smoking status categorized subjects as current smokers or nonsmokers. Alcohol consumption status categorized subjects as current drinkers or nondrinkers; drinkers were also asked about the frequency and daily volume of alcohol intake to calculate their alcohol consumption. We used a validated questionnaire on 24-h physical activity to assess total daily physical activity (metabolic equivalents(MET)-hours). ${ }^{20}$

HRV was measured with a Pulse Analyzer Plus TAS9 device (YKC, Tokyo, Japan). This device is designed to evaluate autonomic nervous function using acceleration pulse waves from the fingertip. HRV was measured once in a 5 -min period in a seated position following a 5-min rest, from June to November from 2009 to 2011, between 0900 and 1200 hours. The participants did not smoke or perform vigorous activity during the 2-to 3-h health-check examination. We used two time domain variables and three frequency domain variables as measurements of HRV. ${ }^{6}$ Time domain variables included the SD of normal R-R intervals (SDNN, MS) and the square root of the mean squared differences of successive R-R intervals (rMSSD, MS). SDNN reflects overall HRV, and rMSSD reflects the activity of the parasympathetic nervous system. ${ }^{6}$ Frequency domain variables included high frequency (HF: $0.15-0.40 \mathrm{~Hz}$ ), low frequency (LF: $0.04-0.15 \mathrm{~Hz}$ ) and the ratio of LF to HF (LF/HF). The HF is an index because variation in parasympathetic nervous system activity reflects the variation, the LF reflects both sympathetic and parasympathetic nervous system activity and LF/HF is an index of sympathetic nervous activity. ${ }^{6}$ We compared HRV between a fasting group (more than $8 \mathrm{~h}$ after a meal) and a nonfasting group (less than $8 \mathrm{~h}$ after a meal); however, no statistically significant differences were found between the fasting group and the nonfasting group.

\section{Statistical analysis}

HRV indices were transformed to natural logarithms because their distributions were skewed. Sex-specific and age-adjusted mean values with respect to SDNN quartiles were calculated by using analysis of covariance. Presence of a linear trend was tested by using the median values of SDNN quartiles.
Linear regression analysis was used to calculate the effects of 1-s.d. increments of HRV indices on blood pressure after adjusting for age, BMI, smoking status, alcohol consumption, total daily physical activity, the use of antihypertensive medication and diabetes. This analysis was also performed after stratification based on the use of antihypertensive mediation.

We further examined the association between HRV and blood pressure levels in men who did not use antihypertensive medication according to alcoholdrinking status because these statuses might have been an effect modifier for the association between HRV and blood pressure levels and also because the proportions of current alcohol drinker were also higher in men. Participants were divided into three categories based on their alcohol consumption as follows: nondrinker ( $0 \mathrm{~g}$ of alcohol per day), light drinker (1-22 g per day) and heavy drinker ( $\geqslant 23 \mathrm{~g}$ per day). Age- and multivariable-adjusted mean values for blood pressure with respect to alcohol-drinking status were calculated using analysis of covariance, with linear regression testing for trends. For all analyses, two-sided probability values of less than 0.05 were considered to be statistically significant. All analyses used the SAS statistical package version 9.1 software (SAS Institute, Cary, NC, USA).

\section{RESULTS}

Table 1 shows sex-specific population characteristics of the subjects. The mean (s.d.) age of participants was 63.1 (8.6) for men and 64.0 (8.0) for women, and $29.4 \%$ of men and $27.5 \%$ of women used

Table 1 Characteristics of study subjects

\begin{tabular}{lcc}
\hline & Men & Women \\
& $\mathrm{n}=1418$ & $\mathrm{n}=2040$ \\
Variables & Mean (s.d.) & Mean (s.d.) \\
\hline Age, years & $63.1(8.6)$ & $64.0(8.0)$ \\
Body mass index, kg m ${ }^{-2}$ & $23.5(3.1)$ & $22.7(3.4)$ \\
Waist circumstances, cm & $84.1(8.4)$ & $81.3(9.6)$ \\
Systolic blood pressure, mm Hg & $132.8(18.3)$ & $130.0(19.4)$ \\
Diastolic blood pressure, mm Hg & $80.0(10.7)$ & $75.1(10.8)$ \\
Heart rate, b.p.m. & $67.2(10.2)$ & $70.0(10.1)$ \\
LDL cholesterol, mmol I-1 & $3.17(0.77)$ & $3.40(0.78)$ \\
HDL cholesterol, mmol I-1 & $1.46(0.38)$ & $1.68(0.40)$ \\
Triglyceride, mmol I-1 a & $1.25(0.91-1.75)$ & $1.08(0.78-1.49)$ \\
HbAlc (JDS), \% & $5.41(0.65)$ & $5.39(0.61)$ \\
Current smoker, \% & 25.0 & 2.6 \\
Regular alcohol drinker, \% ${ }^{-1}$ & 76.3 & 25.5 \\
Alcohol consumption, g per day & $28.2(30.7)$ & $4.4(12.0)$ \\
Daily total physical activity, MET-hourc & $37.7(9.9)$ & $36.6(9.3)$ \\
Hypertension, \% ${ }^{-1}$ & 51.5 & 45.1 \\
Dyslipidemia, \% ${ }^{\text {e }}$ & 53.8 & 60.0 \\
Diabetes, \% ${ }^{f}$ & 11.0 & 6.9 \\
Use of antihypertensive medication, \% & 29.4 & 27.5 \\
& &
\end{tabular}

$\begin{array}{lcc}\text { Heart rate variability } & & \\ \text { SDNN, ms } & & \\ \text { rMSSD, ms } & & \\ \text { a } & 37.9(28.0-53.2) & 34.9(25.8-47.4) \\ \text { In LF, ms } & 29.0(20.0-45.0) & 26.0(19.0-40.0) \\ \text { In HF, ms } & 5.23(1.25) & 4.93(1.24) \\ \text { In LF/HF } & 4.65(1.31) & 4.53(1.25) \\ \end{array}$

Abbreviations: $\mathrm{HbAlc}$, hemoglobin Alc; HDL, high-density lipoprotein; HF, high-frequency power; LDL, low-density lipoprotein; In, natural log; LF, low-frequency power; LF/HF, ratio LF of HF; rMSSD, root mean square of successive differences in R-R intervals; SDNN, s.d. of R-R intervals.

amedian, (interquartile range $25-75 \%$ ).

b Drinking frequency as over one time per week.

cMetabolic equivalents(MET)-hour.

dSystolic blood pressure $\geqslant 140 \mathrm{~mm} \mathrm{Hg}$ and/or diastolic blood pressure $\geqslant 90 \mathrm{~mm} \mathrm{Hg}$ or use of antihypertensive medication.

e HDL cholesterol $\leqslant 1.03 \mathrm{mmol}^{-1}$ or LDL cholesterol $\geqslant 3.62 \mathrm{mmol}^{-1}$ or triglyceride

${ }^{e} \mathrm{HDL}$ cholesterol $\leqslant 1.03 \mathrm{mmol}^{-1}$ or $\mathrm{LDL}$ cholesterol $\geqslant 3.62 \mathrm{~mm}$
$\geqslant 1.69 \mathrm{mmolI}^{-1}$ or pharmacological treatment for dyslipidemia.

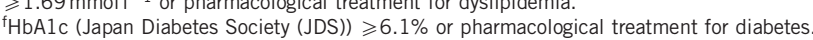




\begin{tabular}{|c|c|c|c|c|c|}
\hline & \multicolumn{5}{|c|}{ SDNN } \\
\hline & Quartile 1 & Quartile 2 & Quartile 3 & Quartile 4 & $\mathrm{P}$ for trend \\
\hline$n$ & 354 & 358 & 351 & 355 & \\
\hline SDNN range, $\mathrm{ms}$ & $8.3-27.9$ & $28.0-37.8$ & $37.9-53.1$ & $53.2-373.1$ & \\
\hline Age, year & 64.8 & 63.0 & 62.9 & 61.6 & $<0.001$ \\
\hline Systolic blood pressure, $\mathrm{mm} \mathrm{Hg}$ & 134.6 & 132.1 & 133.2 & 131.4 & 0.109 \\
\hline Diastolic blood pressure, $\mathrm{mm} \mathrm{Hg}$ & 80.8 & 80.8 & 79.8 & 78.6 & 0.014 \\
\hline Under antihypertensive medication, \% & 39.3 & 25.3 & 30.2 & 22.8 & $<0.001$ \\
\hline Hypertension, \%a & 61.3 & 47.2 & 49.2 & 47.3 & $<0.001$ \\
\hline Diabetes, $\%^{\mathrm{b}}$ & 11.2 & 8.8 & 5.9 & 5.1 & 0.010 \\
\hline \multicolumn{6}{|l|}{ Women } \\
\hline$n$ & 507 & 513 & 510 & 510 & \\
\hline SDNN range, $\mathrm{ms}$ & $6.2-25.7$ & $25.8-34.8$ & $34.9-47.3$ & $47.4-269.2$ & \\
\hline Age, year & 66.6 & 64.1 & 62.5 & 63.0 & $<0.001$ \\
\hline Heart rate, b.p.m. & 76.4 & 70.1 & 67.7 & 66.0 & $<0.001$ \\
\hline Body mass index, $\mathrm{kg} \mathrm{m}^{-2}$ & 22.9 & 22.6 & 22.7 & 22.7 & 0.656 \\
\hline Systolic blood pressure, $\mathrm{mm} \mathrm{Hg}$ & 131.8 & 130.4 & 129.9 & 128.1 & 0.018 \\
\hline Diastolic blood pressure, $\mathrm{mm} \mathrm{Hg}$ & 76.7 & 75.4 & 75.0 & 73.3 & $<0.001$ \\
\hline Under antihypertensive medication, \% & 33.9 & 26.9 & 25.8 & 23.5 & 0.002 \\
\hline Hypertension, $\%^{a}$ & 56.4 & 44.9 & 43.4 & 38.8 & $<0.001$ \\
\hline Diabetes, \% ${ }^{\mathrm{b}}$ & 7.9 & 5.1 & 3.9 & 4.7 & 0.036 \\
\hline
\end{tabular}

Abbreviation: SDNN, s.d. of R-R intervals.

aSystolic blood pressure $\geqslant 140 \mathrm{~mm} \mathrm{Hg}$ and/or diastolic blood pressure $\geqslant 90 \mathrm{~mm} \mathrm{Hg}$, use of antihypertensive medication.

bybA1c (JDS) $\geqslant 6.1 \%$ or pharmacological treatment for diabetes.

cMetabolic equivalents(MET)-hour.

antihypertensive medication. Table 2 shows sex-specific and ageadjusted mean values and proportions according to SDNN quartiles. The lowest quartile of SDNN had the highest age-adjusted mean values for heart rate, BMI, alcohol consumption, and higher prevalence of hypertension and diabetes in men. For women, among all quartiles, the lowest quartile of SDNN had a higher age-adjusted mean value for heart rate, high prevalence of hypertension, diabetes, nondrinkers and lower physical activity. In women, systolic and diastolic blood pressure levels showed graded inverse associations across SDNN quartiles. However, in men, statistically significant trends were only found for diastolic blood pressure levels.

Table 3 shows the correlations between HRV and blood pressure levels after adjusting for age, BMI, smoking status, alcohol consumption, physical activity, use of antihypertensive medication and history of diabetes. For both sexes, SDNN, rMSSD, LF and HF inversely associated with diastolic blood pressure levels, and LF/HF associated positively with diastolic blood pressure levels in the age- and multivariable-adjusted models. A 1-s.d. increment in SDNN was associated with a $-1.00 \mathrm{~mm} \mathrm{Hg}$ decrease in diastolic blood pressure levels for men and a $-1.21 \mathrm{mmHg}$ decrease in diastolic blood pressure levels for women after adjustment for age and other confounders. For women SDNN, rMSSD and HF were inversely associated with systolic blood pressure levels after adjusting for age and the other confounders. However, no statistically significant associations were found between the HRV indices and systolic blood pressure levels in men.

Furthermore, after stratification based on the use of antihypertensive medication, the association between HRV and blood pressure levels was analyzed (Table 4). Inverse associations were slightly evident among individuals not using antihypertensive medication, whereas no significant associations were observed in subjects who used antihypertensive medication.

Figure 1 shows multivariable-adjusted mean levels of systolic blood pressure in men who did not use antihypertensive medication according to alcohol-drinking status. Systolic blood pressure levels showed graded inverse associations across SDNN quartiles in nondrinking men, whereas statistically significant associations between SDNN quartiles and systolic blood pressure levels were not observed among alcohol drinkers. 
Table 3 Predicted differences (s.e.m.) in blood pressure level associated with 1-s.d. increment of HRV indices

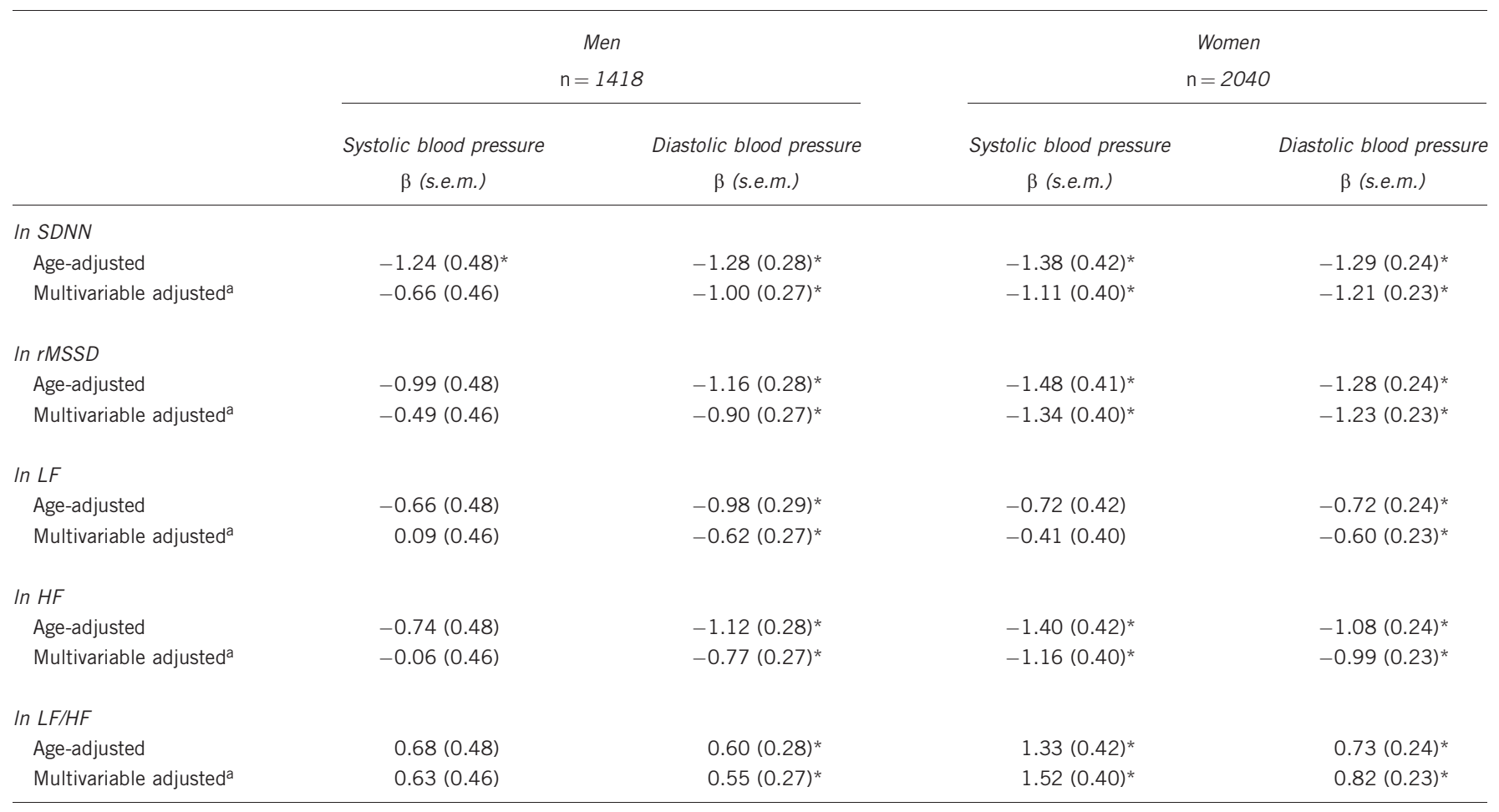

Abbreviations: HF, high-frequency power; HRV, heart rate variability; LF, low-frequency power; In, natural log; LF/HF, ratio LF/HF; rMSSD, root mean square of successive differences in R-R intervals; SDNN, s.d. of R-R intervals.

${ }^{*} P<0.05$.

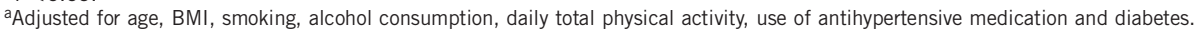

\section{DISCUSSION}

We found significant associations between decreased HRV levels and increased blood pressure independent of several confounders by using the 5-min R-R interval measurement method. ${ }^{6}$ We found a significant inverse association of HRV with diastolic blood pressure, although there was no significant association of HRV with systolic blood pressure. These results are consistent with previous findings for Caucasian populations and confirmed the inverse association between HRV and blood pressure in the Asian population, in which individuals have much lower mean BMIs than those in the United States and Europe. ${ }^{12-14}$

Autonomic imbalance involving hypoactive sympathetic function partially explains the development of hypertension. The autonomic nervous system regulates the maintenance of blood pressure by three mechanisms: direct action on the heart to increase stroke volume, output and heart rate; direct action on peripheral arterial resistance; and by increasing renin level and activity. ${ }^{21}$ Many organs in the human body are dually innervated because they possess both sympathetic and parasympathetic functions. ${ }^{11}$ Sympathetic nerve endings release noradrenalin, which increases cardiac output by increasing heart rate and cardiac muscle automaticity, while increasing vascular resistance in peripheral blood vessels. Therefore, the activation of sympathetic function and subsequent inactivation of parasympathetic function partially contribute to blood pressure elevation.

The inverse association between HRV and blood pressure was not statistically significant in individuals using antihypertensive medication. A previous study showed that antihypertensive medication altered HRV and that the use of $\beta$-blockers was significantly associated with decreased HRV. ${ }^{22}$ Sympathetic hyperactivity was found to be common among younger hypertensive individuals, suggesting that impaired autonomic function might precede the development of hypertension. $^{23}$

This study observed inverse associations between HRV and both systolic and diastolic blood pressures in women. However, systolic blood pressure was not associated with HRV in men. Stratified analysis based on alcohol consumption showed that an inverse association between HRV and systolic blood pressure was present only in male nondrinkers. The Whitehall II study showed that after age adjustment, high alcohol consumption that increases the risk of hypertension ${ }^{24,25}$ was also associated with lower SDNN, LF and HF. ${ }^{16}$ Ohira et al. ${ }^{26}$ found that in 539 Japanese men aged between 35 and 65 years, habitual alcohol intake was associated with increased blood pressure in the morning and heightened sympathetic activity while asleep. In the present study, the proportion of alcohol drinkers was much higher in men than in women. Therefore, the influence of alcohol intake on HRV and blood pressure might have been greater in men, which might have attenuated the association between HRV and systolic blood pressure.

One of the strengths of the present study is the large population size analyzed. In addition, the participants of this study comprise Japanese, who have a lower mean BMI than that of Western populations. We conducted the 5-min R-R interval measurements and investigated the relationship between HRV and blood pressure in accordance with an international standard protocol. ${ }^{6}$ Despite these strengths, this study had several limitations. First, this study was cross-sectional and observational; therefore, it is difficult to discern the causal relationship between HRV and blood pressure level. However, previous studies have shown that decreased HRV is a 
Table 4 Predicted differences (s.e.m.) in blood pressure level associated with 1-s.d. increment of HRV indices by antihypertensive medication use

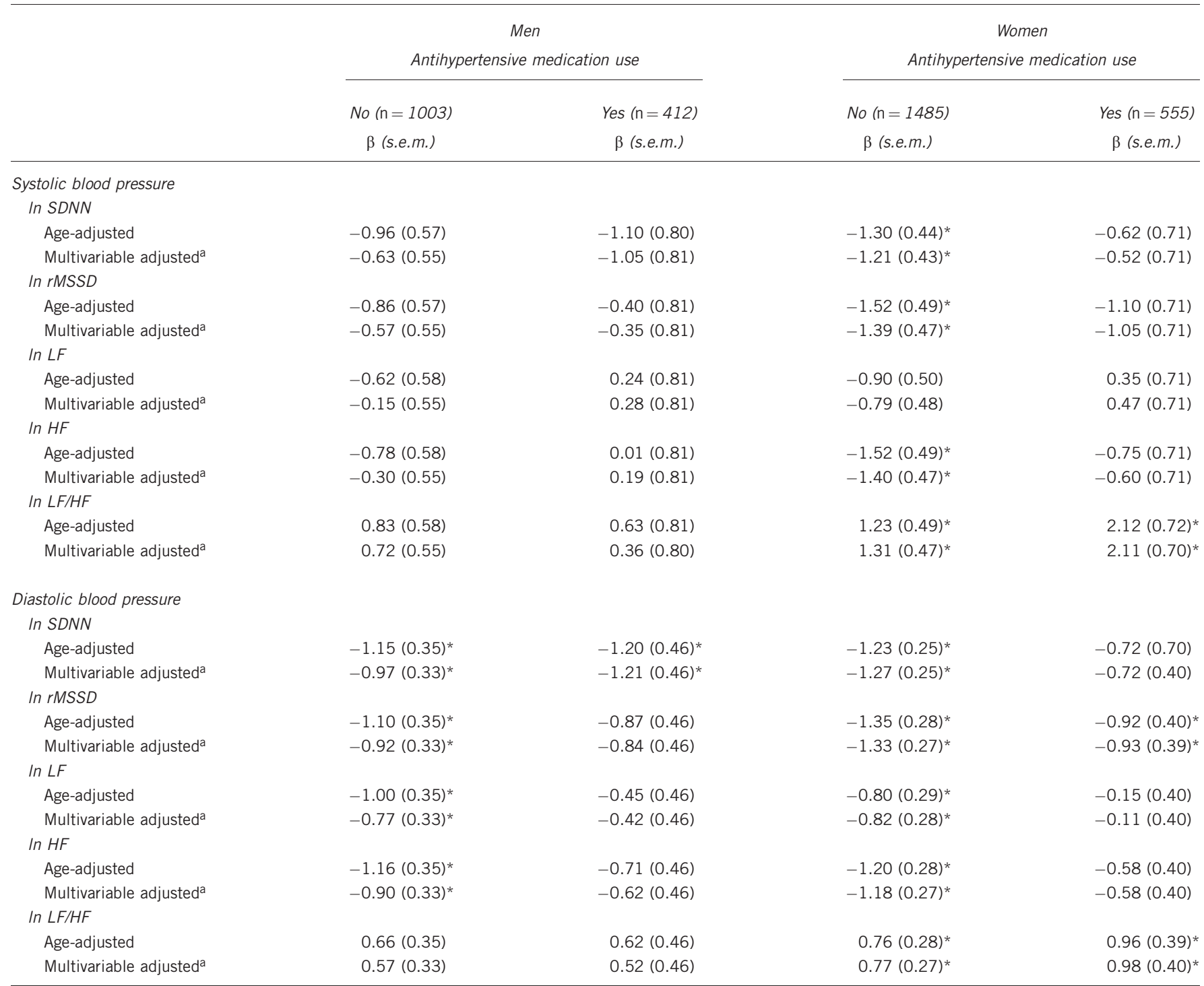

Abbreviations: HF, high-frequency power; HRV, heart rate variability; LF, low-frequency power; LF/HF, ratio LF/HF; In, natural log; rMSSD, root mean square of successive differences in R-R Abbreviations: HF, high-frequency power;

intervals;

${ }^{a}$ Adjusted for age, BMI, smoking, alcohol consumption, daily total physical activity and diabetes.

predictor of hypertension independent of other risk factors. ${ }^{12-14}$ Therefore, we presume that our findings may support a causal relationship of HRV with blood pressure.

Second, although this study was community based, it was not nationally representative: the participants were from a rural area of Japan, although the blood pressure levels and the use of antihypertensive medication were not greatly different from those in a national survey. ${ }^{27}$ Third, salt sensitivity and increased insulin concentrations were not evaluated as confounding factors, although both factors have previously been considered to be associated with sympathetic hyperactivity. ${ }^{28}$ Fourth, because we only used a single HRV and blood pressure measurement for the analyses, we cannot deny the possibility that the circadian variations may have had an effect on the observed associations. Tochikubo et al. ${ }^{29}$ have reported that the maximum value for $\mathrm{LF} / \mathrm{HF}$ and the minimum value for baroreflex sensitivity index can be recorded in the morning. This finding suggests that autonomic nervous function activity has circadian variations, and the effect of circadian variation on HRV may be more evident in the morning. However, in the present study, all HRV measurements were conducted in the morning. Stergiou et al. ${ }^{30}$ have reported that blood pressure levels measured at home had superior reproducibility compared with measurements in clinical settings. Therefore, further studies, including the effect of circadian variation on HRV and individual patient's environment, are needed.

In conclusion, this study suggests that following adjustments for confounders, decreased cardiac autonomic function is associated with increased blood pressure and that the HRV condition strongly reflects diastolic blood pressure levels for both sexes. In men, alcohol intake affects systolic blood pressure levels, which 


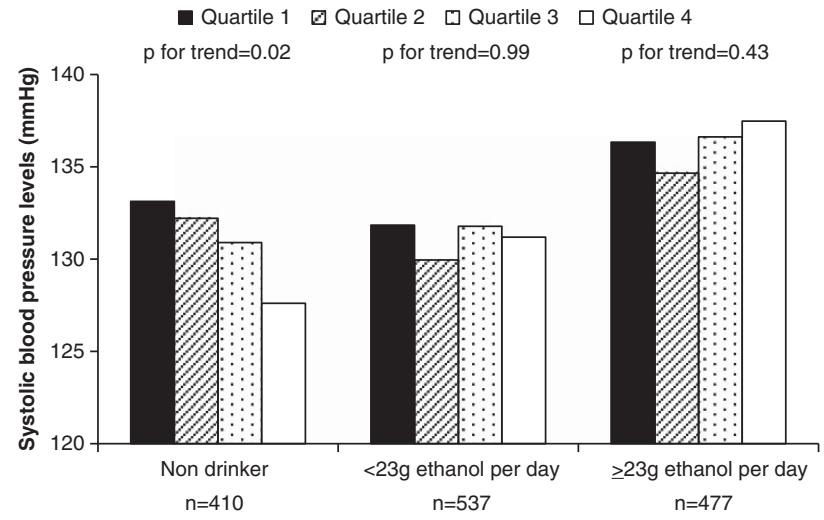

Figure 1 Multivariable-adjusted mean levels of systolic blood pressure according to quartiles of SDNN (s.d. of R-R intervals) with stratification by alcohol-drinking status in men not using antihypertensive medication. Data were adjusted for age, BMI, smoking status, total daily physical activity and presence of diabetes.

may have weakened the association with HRV. Furthermore, this study indicates that a prospective study is needed to better clarify the association of decreased autonomic nervous function with new-onset hypertension and cardiovascular disease in the Japanese population.

\section{ACKNOWLEDGEMENTS}

This study was supported in part by a grant from the Japanese Ministry of Health, Labor and Welfare (Health Labour Sciences Research Grant: 21-003). We thank the investigators, staff and participants in Ozu City for their important contributions.

1 Iso H. Changes in coronary heart disease risk among Japanese. Circulation 2008; 118 2725-2729.

2 Kitamura A, Sato S, Kiyama M, Imano H, Iso H, Okada T, Ohira T, Tanigawa T, Yamagishi K, Nakamura M, Konishi M, Shimamoto T, lida M, Komachi Y. Trends in the incidence of coronary heart disease and stroke and their risk factors in Japan, 1964 to 2003: the Akita-Osaka study. J Am Coll Cardiol 2008; 52: 71-79.

3 Kubo M, Kiyohara Y, Kato I, Tanizaki Y, Arima H, Tanaka K, Nakamura H, Okubo K, lida $\mathrm{M}$. Trends in the incidence, mortality, and survival rate of cardiovascular disease in Japanese community: the Hisayama study. Stroke 2003; 34: 2349-2354.

4 Yusuf S, Hawken S, Ounpuu S, Dans T, Avezum A, Lanas F, McQueen M, Budaj A Pais $\mathrm{P}$, Varigos $\mathrm{J}$, Lisheng $\mathrm{L}$. Effect of potentially modifiable risk factors associated with myocardial infarction in 52 countries (the INTERHEART study): case-control study. Lancet 2004; 364: 937-952.

5 Imano H, Kitamura A, Sato S, Kiyama M, Ohira T, Yamagishi K, Noda H, Tanigawa T, so $\mathrm{H}$, Shimamoto $\mathrm{T}$. Trends for blood pressure and its contribution to stroke incidence in the middle-aged Japanese population: the Circulatory Risk in Communities Study (CIRCS). Stroke 2009; 40: 1571-1577.

6 Heart rate variability: standards of measurement, physiological interpretation and clinical use. Task Force of the European Society of Cardiology and the North American Society of Pacing and Electrophysiology. Circulation 1996; 93: 1043-1065.

7 Liao D, Cai J, Rosamond WD, Barnes RW, Hutchinson RG, Whitsel EA, Rautaharju P, Heiss G. Cardiac autonomic function and incident coronary heart disease: a populationbased case-cohort study. The ARIC Study. Atherosclerosis Risk in Communities Study. Am J Epidemiol 1997; 145: 696-706.
8 Dekker JM, Crow RS, Folsom AR, Hannan PJ, Liao D, Swenne CA, Schouten EG. Low heart rate variability in a 2-minute rhythm strip predicts risk of coronary heart disease and mortality from several causes: the ARIC Study. Atherosclerosis Risk In Communities. Circulation 2000; 102: 1239-1244.

9 Tsuji H, Venditti FJ Jr., Manders ES, Evans JC, Larson MG, Feldman CL, Levy D. Reduced heart rate variability and mortality risk in an elderly cohort. The Framingham Heart Study. Circulation 1994; 90: 878-883.

10 Huikuri HV, Makikallio TH, Airaksinen KE, Seppanen T, Puukka P, Raiha IJ, Sourander LB. Power-law relationship of heart rate variability as a predictor of mortality in the elderly. Circulation 1998; 97: 2031-2036.

11 Thayer JF, Lane RD. The role of vagal function in the risk for cardiovascular disease and mortality. Biol Psychol 2007; 74: 224-242.

12 Liao D, Cai J, Barnes RW, Tyroler HA, Rautaharju P, Holme I, Heiss G. Association of cardiac autonomic function and the development of hypertension: the ARIC study. Am J Hypertens 1996; 9 (12 Pt 1), 1147-1156

13 Schroeder EB, Liao D, Chambless LE, Prineas RJ, Evans GW, Heiss G. Hypertension, blood pressure, and heart rate variability: the Atherosclerosis Risk in Communities (ARIC) study. Hypertension 2003; 42: 1106-1111.

14 Singh JP, Larson MG, Tsuji H, Evans JC, O’Donnell CJ, Levy D. Reduced heart rate variability and new-onset hypertension: insights into pathogenesis of hypertension: the Framingham Heart Study. Hypertension 1998; 32: 293-297.

15 Thayer JF, Yamamoto SS, Brosschot JF. The relationship of autonomic imbalance, heart rate variability and cardiovascular disease risk factors. Int J Cardiol 2010; 141 $122-131$

16 Hemingway H, Shipley M, Brunner E, Britton A, Malik M, Marmot M. Does autonomic function link social position to coronary risk? The Whitehall II study. Circulation 2005 111: 3071-3077

17 Chobanian AV, Bakris GL, Black HR, Cushman WC, Green LA, Izzo JL Jr., Jones DW, Materson BJ, Oparil S, Wright JT Jr., Roccella EJ. The Seventh Report of the Joint National Committee on Prevention, Detection, Evaluation, and Treatment of High Blood Pressure: the JNC 7 report. JAMA 2003; 289: 2560-2572.

18 Kuzuya T, Nakagawa S, Satoh J, Kanazawa Y, Iwamoto Y, Kobayashi M, Nanjo K, Sasaki A, Seino Y, Ito C, Shima K, Nonaka K, Kadowaki T. Report of the Committee on the classification and diagnostic criteria of diabetes mellitus. Diab Res Clin Pract 2002; 55: 65-85.

19 Teramoto T, Sasaki J, Ueshima H, Egusa G, Kinoshita M, Shimamoto K, Daida H, Biro S, Hirobe K, Funahashi T, Yokote K, Yokode M. Executive summary of Japan Atherosclerosis Society (JAS) guideline for diagnosis and prevention of atherosclerotic cardiovascular diseases for Japanese. J Atheroscler Thromb 2007; 14: 45-50.

20 Fujii H, Yamamoto S, Takeda-Imai F, Inoue M, Tsugane S, Kadowaki T, Noda M. Validity and applicability of simple questionnaire for the estimation of total and domainspecific physical activity. Diabetol Int 2011; 2: 47-54.

21 Julius S, Nesbitt S. Sympathetic overactivity in hypertension. A moving target. Am J Hypertens 1996; 9: 113S-120S

22 Tsuji H, Venditti FJ Jr., Manders ES, Evans JC, Larson MG, Feldman CL, Levy D. Determinants of heart rate variability. J Am Coll Cardiol 1996; 28: 1539-1546.

23 Julius S, Valentini M, Palatini P. Overweight and hypertension: a 2-way street? Hypertension 2000; 35: 807-813.

24 Fuchs FD, Chambless LE, Whelton PK, Nieto FJ, Heiss G. Alcohol consumption and the incidence of hypertension: the Atherosclerosis Risk in Communities Study. Hypertension 2001; 37: 1242-1250.

25 Briasoulis A, Agarwal V, Messerli FH. Alcohol consumption and the risk of hypertension in men and women: a systematic review and meta-analysis. J Clin Hypertens (Greenwich) 2012; 14: 792-798

26 Ohira T, Tanigawa T, Tabata M, Imano H, Kitamura A, Kiyama M, Sato S, Okamura T, Cui R, Koike KA, Shimamoto T, Iso H. Effects of habitual alcohol intake on ambulatory blood pressure, heart rate, and its variability among Japanese men. Hypertension 2009; 53: 13-19.

27 Ministry of Health Law. Nutrition Status Based On The National Nutrition Survey In Japan. Daiichi Shuppan, Tokyo, Japan, 2012.

28 Yatabe MS, Yatabe J, Yoneda M, Watanabe T, Otsuki M, Felder RA, Jose PA, Sanada H. Salt sensitivity is associated with insulin resistance, sympathetic overactivity, and decreased suppression of circulating renin activity in lean patients with essential hypertension. Am J Clin Nutr 2010; 92: 77-82.

29 Tochikubo O, Kawano Y, Miyajima E, Toshihiro N, Ishii M. Circadian variation of hemodynamics and baroreflex functions in patients with essential hypertension. Hypertens Res 1997; 20: 157-166.

30 Stergiou GS, Baibas NM, Gantzarou AP, Skeva II, Kalkana CB, Roussias LG, Mountokalakis T. Reproducibility of home, ambulatory, and clinic blood pressure: implications for the design of trials for the assessment of antihypertensive drug efficacy. Am J Hypertens 2002; 15 (2 Pt 1), 101-104. 